\title{
PRODUCTION PROCESS EVALUATION FOR EARTHWORKS
}

\author{
Eran Haronian ${ }^{1}$ and Rafael Sacks ${ }^{2}$
}

\begin{abstract}
Production in earthworks projects is a continuous process of strictly sequenced operations performed by heavy machinery on site. The Production Process Evaluation (PPE) index was developed to evaluate these types of processes by quantifying waste in the bottleneck operation. The PPE index is the ratio of the actual production volume to the theoretical maximum production volume, and it is calculated by assessing value adding and nonvalue adding times, actual and theoretical throughput, and shift durations. These are computed using data obtained from machine control systems linked to the roadel information schema, which represents continuous products and processes. The PPE index was implemented on a case study of a water reservoir construction project. The spreading operation was identified as the bottleneck in the process, based on the high levels of inventory waiting for the operation, the high capacity utilization in the operation and the low capacity utilization of the predecessor and successor operations. The PPE index ranged from $45 \%$ to $54 \%$ during the three weeks of the case study and indicated high levels of waste in the bottleneck and a lack of production management.
\end{abstract}

\section{KEYWORDS}

Bottleneck, earthworks, production, waste, workflow

\section{INTRODUCTION}

The potential of LC for earthworks and road construction has been recognized for a long time (Drysdale 2013). However, the potential remains unfulfilled. Tezel et al. (2018) investigated the condition of Lean Construction (LC) in highway construction projects and found "shallow, partial or selective lean adoption"; despite "strong external motivations", there was a "pseudo-lean" environment. Earthworks comprise a major portion of highway construction, and their continuous nature appears to be a major barrier to lean production planning and control. Studies on the subject mostly adopt a Design Science Research (DSR) approach and include development of technological tools or managerial techniques, such as the digital Kanban (Kirchbach et al. 2014) or visual management in general (Tezel and Aziz 2017).

In recent years, significant progress has been made in machine control technologies for earthworks, and implementation rates have increased accordingly. These technologies allow automation of significant portions of works and provide real-time and continuous monitoring of the operations. While the significant improvement on the operational level

$1 \quad \mathrm{PhD}$ Candidate, Seskin Virtual Construction Laboratory, Faculty of Civil and Environmental Engineering, Technion - IIT, eranha@campus.technion.ac.il, orcid.org/0000-0001-9056-1722

2 Professor, Seskin Virtual Construction Laboratory, Faculty of Civil and Environmental Engineering, Technion - IIT, cvsacks@technion.ac.il, orcid.org/0000-0001-9427-5053 
is clear and can be quantified (Sturm and Vos 2008), no consideration has been given to the way these technologies can be harnessed for process improvement.

This study contributes a new tier in the application of LC to earthworks, as machine control data is utilized for production process evaluation. The DSR approach is adopted: an artefact in the form of a production indicator is developed and implemented on a case study, enabling a new perspective on production in earthworks.

Drucker's saying "you can't manage what you can't measure" reflects the core motivation for the development of production flow measurements in construction. One widely used indicator is the Percent Plan Complete (PPC) index, which is an integral part of the Last Planner System (Ballard 2000). PPC measures the reliability of production planning, its ability to define work packages, remove constraints, allocate resources, schedule tasks, and execute planned work as scheduled. The Construction Workflow Index (CWI), is another example of a production flow indicator (Priven et al. 2014; Sacks et al. 2017). CWI is based on Little's Law's basic parameters (Little and Graves 2008) and on a graphical-mathematical analysis of the location-based schedules.

Most Lean Construction research and development has been conducted in the building construction domain, and less in the infrastructure and earthworks domain. As a result, no production flow measurements have been developed to address the unique processes found in these types of projects. The production process of earthworks projects differs from the production processes found in most building construction projects. Earthworks projects, such as highways, railways, site development, and earth dams have continuous layered elements. Unlike buildings, which are composed of discrete products, many of which are manufactured in factories and installed on-site by professional work teams, layered elements are continuous and involve material processing by heavy equipment on site. Characteristics of continuous flow and process manufacturing dominate the process in earthworks:

- Material processing is a core component of production: excavating, grinding, compacting, paving, etc.

- Real time quantity calculation systems are required for controlling consumed resources and for monitoring production status.

- Finished products can be disassembled only through demolition (unlike assembled components in a building).

Table 1 summarizes some of the key differences between earthworks and building construction. According to Shingo: "Process analysis examines the flow of material or product; operation analysis examines the work performed on products by worker and machine (Shingo and Dillon 1989)." Digital machine control and remote sensing technologies improve operations such as excavation, material spreading, and compaction. However, processes flow improvements require the development of semantic concepts and production flow measurements that enable process evaluation and improvement.

As part of a broader effort to develop, implement and test the concepts and tools needed for lean production control in earthworks projects, we present a Production Process Evaluation (PPE) index for layered elements, based on data obtained from machine control technologies. The paper includes three sections. The first section describes the production process of layered elements and outlines the typical types of waste involved. In the second section, the PPE index is presented, and the calculation procedure is described. The third section outlines a case study in which the PPE index was tested over a period of three weeks. We conclude with a discussion on the index and 
on the general applicability of Lean Construction principles and techniques for projects with continuous layered elements.

Table 1: Production characteristics of earthworks and of buildings (Haronian and Sacks 2018, 2019)

\begin{tabular}{|c|c|c|}
\hline & Earthworks & Building construction \\
\hline Product & $\begin{array}{l}\text { One of a kind } \\
\text { Continuous } \\
\text { No customization } \\
\end{array}$ & $\begin{array}{l}\text { One of a kind } \\
\text { Discrete } \\
\text { High customization }\end{array}$ \\
\hline \multirow[t]{3}{*}{ Process } & $\begin{array}{l}\text { Materials produced on site (by digging, } \\
\text { crushing and mixing) }\end{array}$ & $\begin{array}{l}\text { Primarily components manufactured in } \\
\text { a factory, transferred to site and } \\
\text { installed }\end{array}$ \\
\hline & $\begin{array}{l}\text { Much of the work is "material } \\
\text { processing" } \\
\text { Few task types, few subcontractors }\end{array}$ & $\begin{array}{l}\text { Much of the work is "assembly" } \\
\text { Many task types, many subcontractors }\end{array}$ \\
\hline & $\begin{array}{l}\text { Location breakdown structure is } \\
\text { governed by external constraints } \\
\text { Technological and safety aspects prevent } \\
\text { execution of several tasks simultaneously } \\
\text { in the same working area }\end{array}$ & $\begin{array}{l}\text { The location breakdown structure is } \\
\text { defined by the sub-products (floors, } \\
\text { apartments, etc.) } \\
\text { Several tasks can be performed } \\
\text { simultaneously in the same working } \\
\text { area }\end{array}$ \\
\hline Resource & Heavy machinery is the main resource & $\begin{array}{l}\text { Professional workers are the main } \\
\text { resource }\end{array}$ \\
\hline
\end{tabular}

\section{PRODUCTION OF LAYERED ELEMENTS}

Production of layered elements is an integral part of road construction, railway superstructure, embankments, and almost any project that involves earthworks. The typical production process of layered elements includes the following operations:

1. Marking of layer boundaries by a surveyor according to design (automated machine control technology can obviate the need for this step).

2. Material supply from excavation on site, from a quarry, or from any other source.

3. Material spreading for a layer according to the designed layer thickness and in the proper location. This operation is performed by dedicated heavy machinery, such as motor-graders and bulldozers.

4. Layer moistening to the required moister percentage (optimum soil moisture levels for compaction must be determined from a proctor curve prepared by an engineering soils laboratory).

5. Compaction of layers according to the designed compaction measurements.

6. Quality tests after compaction, by soils laboratory and by the surveyor.

The process is illustrated in Figure 1.

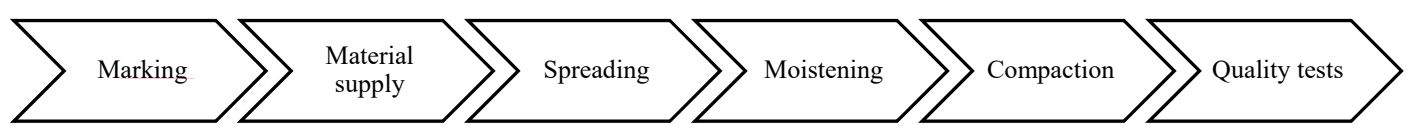

Figure 1: Layered elements production process 
Most of the generic waste types defined by Womack and Jones (1996) can be found in the layered elements production process:

1. Over-processing in the form of overfill, as material is spread beyond the design boundaries.

2. Waiting times of the resources or the products. Resource waiting time occurs during the operations, for example when spreading equipment is waiting for material supply, or between operations as the equipment is waiting for completion of preceding tasks. Product waiting times reflect the times when no operation is performed on a location that is under production.

3. Transportation of material and resources, across the site from one location to another.

4. Inventory and Work in Process (WIP) in the format of locations where production has begun but has not finished yet.

5. Motion of machinery or workers across the site.

6. Over-processing by compaction beyond specifications.

7. Defects in layers that do not meet specifications after the compaction.

In general, various forms of waste appear together and are strongly correlated. For example, high rates of WIP increase the product waiting times, transportation and motion increase resource waiting time, etc. The PPE index is calculated based on the two dominant types of wastes: over-processing and resource waiting times. These wastes indicate the production flow quality and suffice for computing an index.

\section{PRODUCTION PROCESS EVALUATION (PPE)}

The times in each operation can be divided into several categories, as detailed in Table 2. The shift time is the total amount of time assigned for an operation. The gross working time is the actual time that the operation was available for work on site. Over-processing times and waiting times reflect the non-value adding times. Net processing time is calculated by subtracting the waiting times from the gross working times (overprocessing time is not subtracted as they are still processing times). Value adding time is the time spent on correct processing of work and can be calculated by subtracting the nonvalue adding times from the net working time.

Table 2: Time categories in earthworks operations

\begin{tabular}{|l|l|}
\hline Time category & Definition \\
\hline Shift time & The total time assigned for an operation \\
\hline Gross working time & $\begin{array}{l}\text { The actual time that the operation was available } \\
\text { for work on site }\end{array}$ \\
\hline Over-processing time & Time wasted on over-processing \\
\hline Waiting times in work packages & Time wasted on waiting in the work packages \\
\hline Net processing time & Gross working time minus waiting time \\
\hline Value adding time & Time spent in correct work \\
\hline
\end{tabular}

The production process evaluation (PPE) index is based on an analysis of the bottleneck operation in the process. The bottleneck operation is the operation that limits the capacity of the entire process, and can be identified by two indicators; the amount of inventory 
before a workstation, and the high levels of capacity utilization of the resources (Goldratt and Cox 1984).

The theoretical throughput of the bottleneck operation can be calculated by dividing the production volume in the bottleneck (including over-processing), by the net processing times (Equation 1). Accordingly, the PPE index can then be calculated as the ratio of the actual production to the theoretical throughput rate multiplied by the shift time (Equation 2).

Equation 1:

$$
\text { Theoretical Throughput }=\frac{\text { Production volume }[\mathrm{UoM}]}{\text { Net processing time }[\mathrm{hr}]}
$$

Equation 2:

$$
\text { Production Process Evaluation }=\frac{\text { Actual Value Added Output [UoM }]}{\text { Theoretical Throughput }\left[\frac{\mathrm{UoM}}{\mathrm{hr}}\right] \times \text { Total shift time }[\mathrm{hr}]}
$$

\section{CASE STUDY}

\section{BACKGROUND}

The case study on which the PPE index will be demonstrated is the construction of the embankments for a water reservoir. A picture of the water reservoir under construction is presented in Figure 2, and a plan view of the embankment in Figure 3.

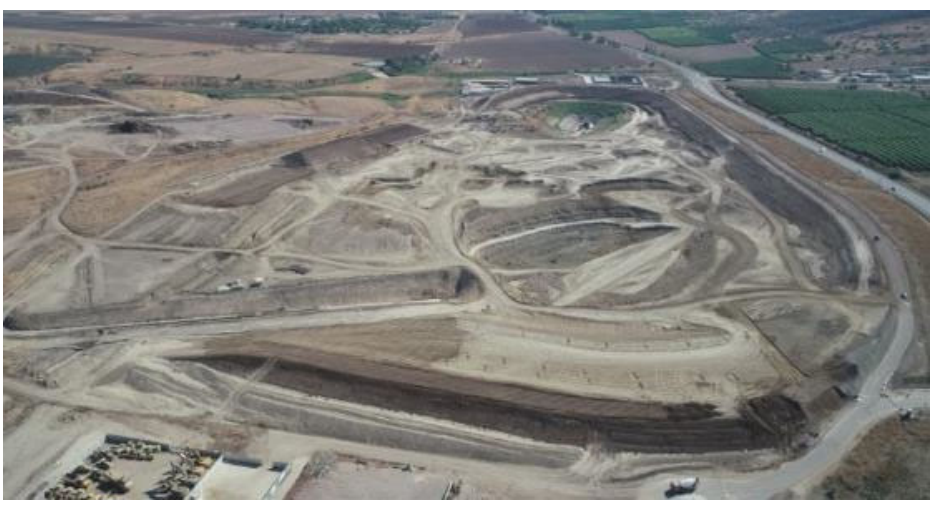

Figure 2: Picture of water reservoir under construction

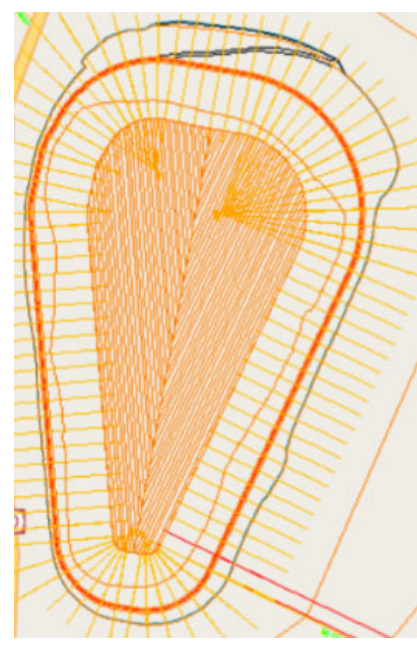

Figure 3: Plan of reservoir

The embankment is produced from clay in layers of $25 \mathrm{~cm}$. The number of layers required varies from over 80 to less than 10, depending on the existing base elevation and the planned top elevation in each location. The project is located in an area with an arid climate where the temperature rises to $45^{\circ} \mathrm{C}$ in the summer. The clay was excavated on site and contained suitable moisture levels for compaction, however once spread, the material dried rapidly. Therefore, it was of great importance to carry out the work continuously and avoid delays between the spreading and compaction operations and minimize the additional operation of soil moistening. 


\section{BOTTLENECK IDENTIFICATION}

Observations on site indicated that the spreading operation was the bottleneck in the production process. Two machines, a CAT 140M motor-grader and a CAT D6 bulldozer, were available for the spreading operation, and they were used in parallel. Two significant phenomena were observed:

1. High levels of product inventory in the form of locations under construction, where all preceding operations had been completed and all constraints had been removed, waiting for the spreading operation to be performed (Figure 4).

2. Low resource utilization levels in the predecessor and successor operations.

3. Figure 5 shows a waiting queue of trucks with material supply for the spreading operation, and Figure 6 shows a compactor without any work, waiting for the spreading operation to finish.

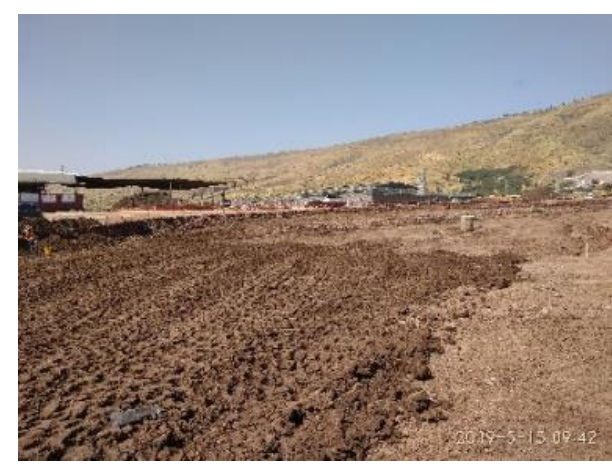

Figure 4: Location waiting for spreading operation

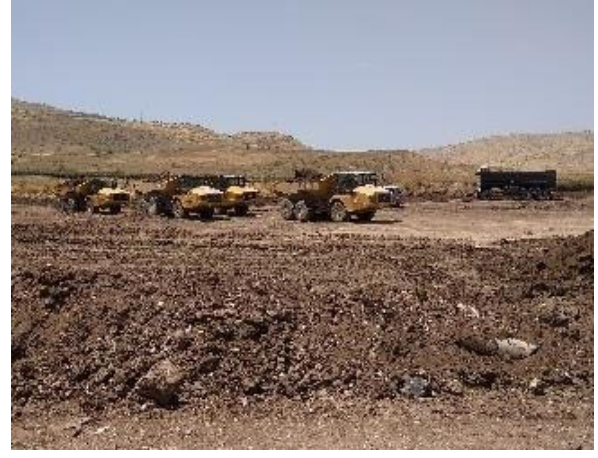

Figure 5: Trucks with material supply waiting

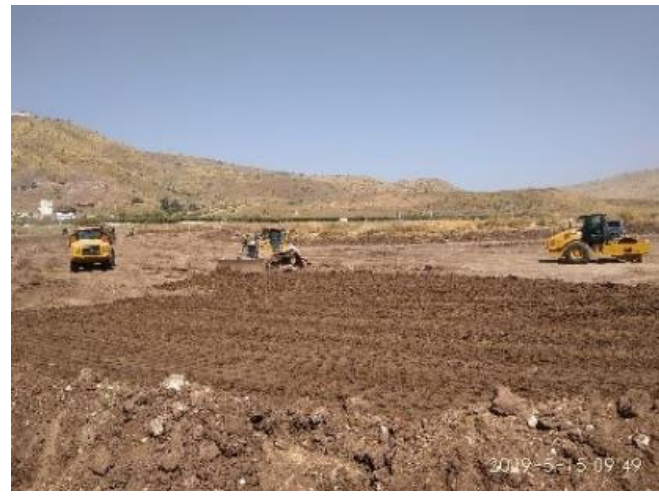

Figure 6: Compactor waiting for spread operation to finish

Once the bottleneck operation was identified, the next step was to analyze the bottleneck operation and to quantify wastes on the operational level.

\section{Work Monitoring ANd Data Analysis}

Data for production analysis was generated from machine control systems installed on the heavy equipment in the project. The machine control systems used were Trimble 
Grade Control System for the motor-grader and the dozer (Figure 7), and Trimble Compaction Control System for the compactors (Figure 8).
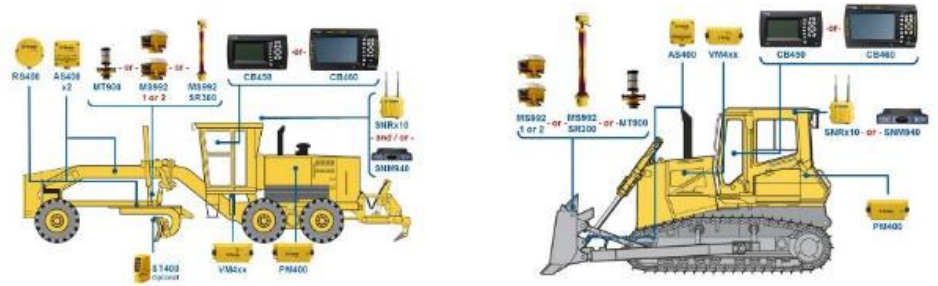

Figure 7: Trimble grade control systems

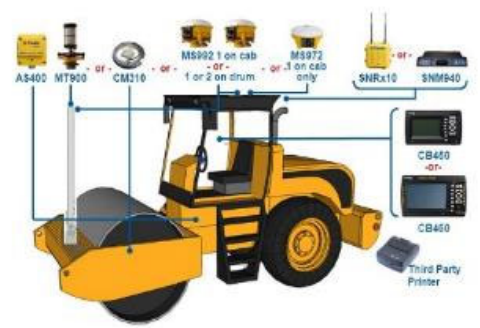

Figure 8: Trimble compaction control systems

The data analysis procedure was based on the Roadel information schema presented by Haronian and Sacks $(2018,2019)$. This schema uses discrete elements to represent continuous elements, such as the layers of roads, as illustrated in Figure 9. A roadel is a unit element of a road course layer, much as a pixel is unit element of a picture. Each element represents a sub-product and enables storage of design information (such as layer properties), and storage of production information, including a complete record of all the operations performed on each layer in the element.

Accordingly, the embankment was divided into 75,000 roadels (discrete elements), and the data obtained from machine control systems was linked to the appropriate elements.

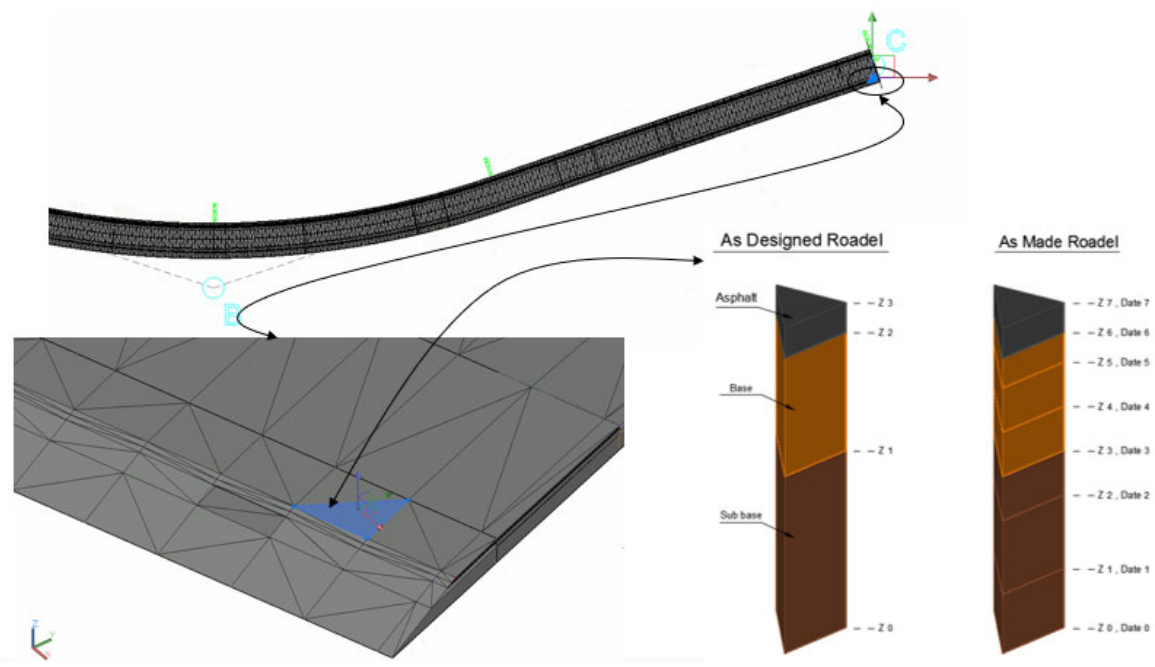

Figure 9: Schematic illustration of the roadel information schema

(Haronian and Sacks 2019) 


\section{PPE CALCUlation}

For the PPE calculation, two types of wastes were quantified:

1. Over-processing in the form of material overfill outside the design boundary, during the spreading operation.

2. Resource waiting times while preforming work packages and between work packages.

The PPE index was calculated on a weekly basis over a period of three weeks.

\section{Over-processing}

Over-processing in spreading operations occurs when excess material is spread outside and/or above the design boundaries for the layers of the embankment, as shown in Figure 10. The calculation was done on each discrete roadel, according to its design elevation, as-made elevation, and area (for volume calculation). In equation 3 , di is the elevation of each roadel, where $i$ has values from 1 to 75,000 . didesign is the designed elevation for roadel i, di,jas-made is the as-made elevation for each roadel measured at the end of week $\mathrm{j}$, and hi,joverfill represents the excess in week $\mathrm{j}$, calculated using the algorithm defined in Equation 3. The overfill volume (the over-processing in this case) can then be calculated for each roadel according to its area Ai, as shown in Equation 4.

Equation 3:

$$
\boldsymbol{h}_{\mathrm{i}, \mathrm{j}}^{\text {overfill }}=\left\{\begin{array}{c}
\boldsymbol{d}_{\mathrm{i}}^{\text {design }}>\boldsymbol{d}_{\mathrm{i}, \mathrm{j}}^{\text {as-made }} \rightarrow \boldsymbol{h}_{\mathrm{i}, \mathrm{j}}^{\text {overfill }}=\mathbf{0} \\
\boldsymbol{d}_{\mathrm{i}}^{\text {design }}<\boldsymbol{d}_{\mathrm{i}, \mathrm{j}-1}^{\text {as-made }} \rightarrow \boldsymbol{h}_{\mathrm{i}, \mathrm{j}}^{\text {overfill }}=\boldsymbol{d}_{\mathrm{i}, \mathrm{j}}^{\text {as-made }}-\boldsymbol{d}_{\mathrm{i}, \mathrm{j}-1}^{\text {as-made }} \\
\boldsymbol{d}_{\mathrm{i}}^{\text {design }}<\boldsymbol{d}_{\mathrm{i}, \mathrm{j}}^{\text {as-made }} \rightarrow \boldsymbol{h}_{\mathrm{i}, \mathrm{j}}^{\text {overfill }}=\boldsymbol{d}_{\mathrm{i}, \mathrm{j}}^{\text {as-made }}-\boldsymbol{d}_{\mathrm{i}}^{\text {design }}
\end{array}\right\}
$$

Equation 4:

$$
\text { Overproduction }_{\text {week } j}=\sum_{1}^{n} \boldsymbol{A}_{\mathrm{i}} \frac{\boldsymbol{h}_{\mathrm{i}, \mathrm{j}}^{\text {overfill }}}{\boldsymbol{d}_{\mathrm{i}}^{\text {design }}}
$$

Assuming that the raw production rate for overfill was the same as the production rate for the fill as a whole, the durations of over-processing in the operations were evaluated using the over-processing proportion.

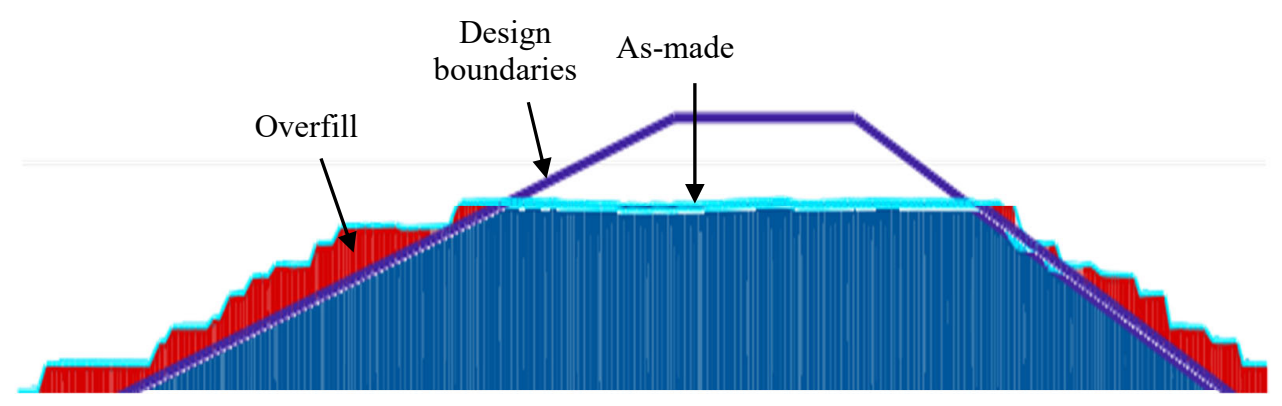

Figure 10: Over-processing in spreading operations

(Image from Trimble VisionLink) 


\section{Resource Waiting Time}

Resource waiting times are times during the work package when the resource stopped working on the operation. Table 3 presents a sample of waiting times for five work packages.

Table 3: Sample of waiting times in work packages

\begin{tabular}{|c|l|c|c|}
\hline Operation & Resource & Work package duration & Waiting times \\
\hline Spreading & Dozer D6T & $8: 27: 10$ & $3: 55: 42$ \\
\hline Spreading & Dozer D6T & $7: 06: 48$ & $3: 03: 49$ \\
\hline Spreading & Dozer D6T & $4: 45: 03$ & $0: 13: 05$ \\
\hline Spreading & Grader 140M3 & $4: 02: 50$ & $1: 11: 29$ \\
\hline Spreading & Grader 140M3 & $4: 03: 16$ & $0: 34: 49$ \\
\hline
\end{tabular}

The diagram in Figure 11 illustrates the work path of the D6T dozer while executing a spreading operation. Axes $\mathrm{X}$ and $\mathrm{Y}$ represent the $\mathrm{E}$ and $\mathrm{N}$ geo-coordinates, and axis $\mathrm{Z}$ represents the timeline in decimal units. The gaps that can be seen on the timeline in the perspective view indicate that the D6T remained stationary for certain periods of time, which reflects the waiting times.
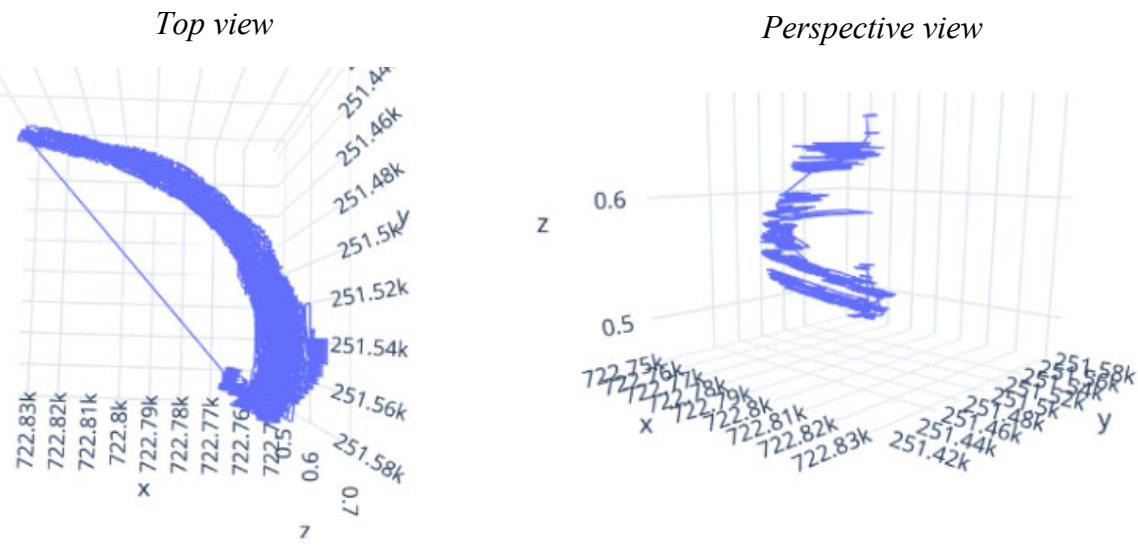

Figure 11: Work path of D6 dozer during spread operation

\section{Results - Production Process evaluation}

The PPE index was calculated separately for each of three weeks of the case study. A distinction is made between 'actual production volume' and 'total processing volume'. The actual production volume for each week is quantified by the total volume of complete layers excluding overfill, while the total processing volume includes the overfill and relates to the theoretical throughput calculation. The working areas for each week are presented in Figure 12, and a summary of the parameters and the PPE results for each week are presented in Table 1.

The PPE index indicates that the production level of the bottleneck, and the process in general, is approximately $50 \%$ of its full potential. The low PPE level reflects the wastes in the process, especially the resource waiting times and the over-processing times, thus any reduction of wastes will increase the PPE.

The results point out a typical bottleneck scenario in the spread operation - high capacity rates combined with low efficiency. The value-adding times of the bottleneck were only $36 \%-58 \%$ of the total shift times, reflecting low efficiency, while the total 
working times reached $85-92 \%$ of the shift time, reflecting high capacity. The PPE index for the three weeks of the case study was $45 \%-54 \%$, indicating poor production management practice, and calling for a systemic solution.

Table 1: PPE results for three weeks of the case study

\begin{tabular}{|l|c|c|c|}
\hline Week & $\mathbf{3 2}$ & $\mathbf{3 5}$ & $\mathbf{3 7}$ \\
\hline Shift time [h:m] & $122: 00$ & $122: 00$ & $122: 00$ \\
\hline Gross working time [h:m] & $103: 57$ & $107: 54$ & $112: 41$ \\
\hline Waiting times in work packages [h:m] & $55: 11$ & $35: 08$ & $35: 25$ \\
\hline Net processing times [h:m] & $48: 45$ & $72: 45$ & $77: 16$ \\
\hline Over-processing time [h:m] & $5: 10$ & $17: 53$ & $6: 56$ \\
\hline Value adding time [h:m] & $43: 35$ & $54: 51$ & $70: 19$ \\
\hline Non-value adding time [h:m] & $78: 24$ & $67: 08$ & $51: 40$ \\
\hline Production volume (Total fill) $\left[\mathrm{m}^{3}\right]$ & 19,465 & 20,620 & 19,745 \\
\hline Over production $\left(\right.$ Over fill) $\left[\mathrm{m}^{3}\right]$ & 2,062 & 5,073 & 1,773 \\
\hline Actual Production $\left[\mathrm{m}^{3}\right]$ & 17,402 & 15,547 & 17,972 \\
\hline Theoretical Throughput $\left[\mathrm{m}^{3} / \mathrm{hr}^{3}\right]$ & 267 & 283 & 271 \\
\hline PPE [\%] & $53 \%$ & $45 \%$ & $54 \%$ \\
\hline
\end{tabular}

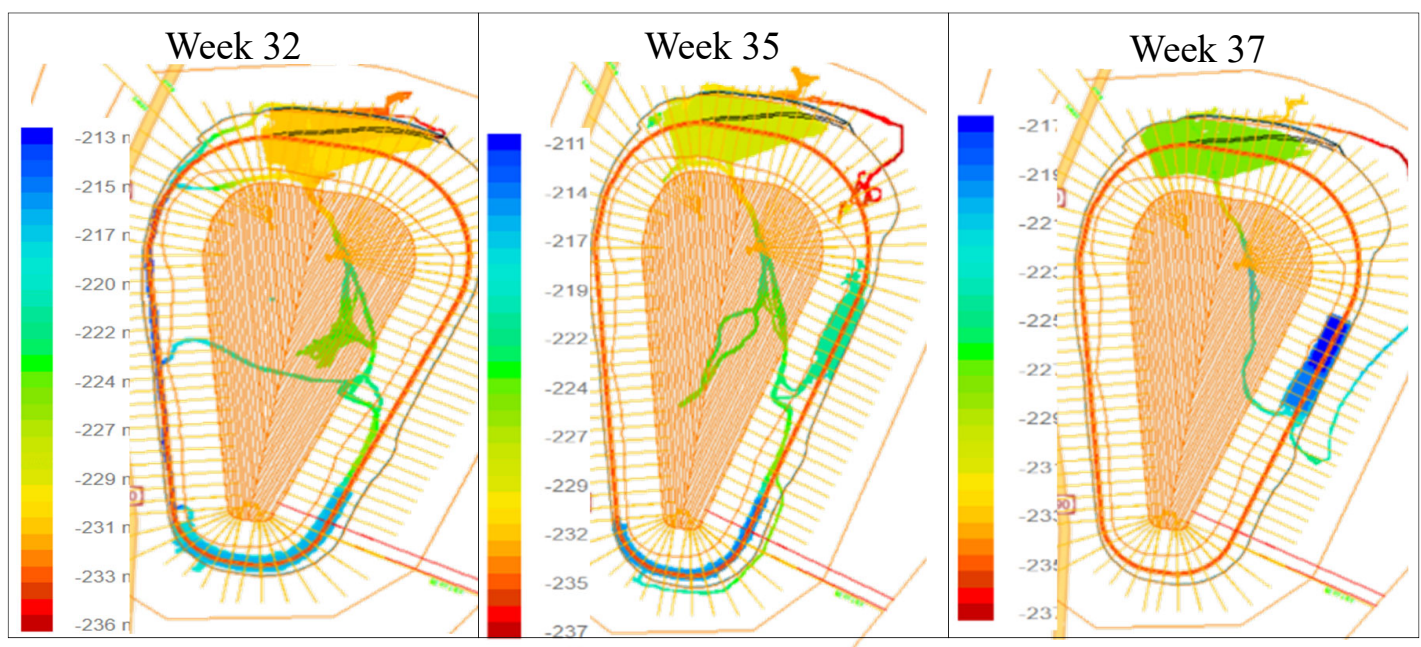

Figure 12: Work areas for each week, color-coded by elevation (Images from Trimble VisionLink software)

The PPE index points to the wastes, but their causes must be revealed by root cause or ' 5 why analysis' (for example, the resource waiting times may be caused by a lack of training of the machine operator, by the way the materials are supplied, or by other reasons). It should be noted that an improvement in the bottleneck operation may lead to the formation of a new bottleneck (Goldratt and Cox 1984).

\section{DISCUSSION}

Production of layered elements, and earthworks in general, is characterized as a material processing process by a strict sequence of machine operations that produce continuous products. Unlike most production flow indicators (such as the PPC and CFI) that have 
been developed for the building construction environment, the PPE index is the first production flow indicator developed specifically to evaluate this type of production.

The PPE calculation is based on data obtained by machine control systems used in earthworks construction, and on the roadel information schema that enables discrete representation of continuous elements. Similarly, other established production flow indicators that mostly rely on manual work, may evolve and be linked to new monitoring and automation technologies.

The PPE index integrates well with the growing potential for continuous monitoring and evaluation of production in construction projects. The PPE index can be further developed to include analysis of all the operations in the production process and not only the bottleneck. This may enable continuous improvement across the production process, cost reductions, and improved value generation.

\section{CONCLUSIONS}

Lean construction for earthworks and road construction may have a significant impact, starting from the way operations are implemented, including aspects of technology adoption, and continuing with process and production managed on-site. The conceptual understanding of production waste in these types of projects is commonly undeveloped, evidenced by a narrow focus on cost overruns and schedule delays. The potential impact of Lean construction is demonstrated, as the PPE index enables both identification and quantification of waste on the production level. The study is limited to one case study of an embankments project. However, although adjustments may be required, the PPE index and the roadel information schema may support production control on a variety of earthwork and infrastructure projects. This study demonstrates how new technologies that have been designed for operational improvements can be utilized for process analysis and to support production management.

Further implementation of Lean construction for earthworks construction projects requires thorough development and adaptation of Lean production theory, principles, and tools.

\section{REFERENCES}

Ballard, H.G. (2000). “The Last Planner System of Production Control.” PhD Diss., The University of Birmingham, England.

Drysdale, D. (2013). "Introducing Lean Improvement into the UK Highways Agency Supply Chain.” Proc. 21st Ann. Conf. Int. Group for Lean Constr., Fortaleza, Brazil.

Goldratt, E.M., and Cox, J. (1984). The Goal: a Process of Ongoing Improvement. North River Press, Great Barrington, MA.

Haronian, E. and Sacks, R. (2018). "A Specialized Information Schema for Production Planning and Control of Road Construction." Proc. 12th European Conference on Product and Process Modelling, Copenhagen, Denmark.

Haronian, E. and Sacks, R. (2019). "Roadels: Discrete Information Objects for Production Planning and Control of Road Construction." Journal of Information Technology in Construction, Special issue ECPPM 2018.

Kirchbach, K., Koskela, L., and Gehbauer, F. (2014). "Digital Kanban for Earthwork Site Management." Proc. $22^{\text {nd }}$ Ann. Conf. Int. Group for Lean Constr., Oslo, Norway. Little, J.D. and Graves, S.C. (2008). "Little's Law." Building Intuition, Springer, 81-100. 
Priven, V., Sacks, R., Seppänen, O., and Savosnick, J. (2014). “A Lean Workflow Index for Construction Projects." Proc. 22 ${ }^{\text {nd }}$ Ann. Conf. Int. Group for Lean Construction, Oslo, Norway, 715-726.

Sacks, R., Seppänen, O., Priven, V., and Savosnick, J. (2017). "Construction Flow Index: a Metric of Production Flow Quality in Construction." Construction Management and Economics, 35(1-2), 45-63.

Shingo, S. and Dillon, A. P. (1989). A Study of the Toyota Production System: From an Industrial Engineering Viewpoint. Productivity Press, Portland, Oregon, USA.

Sturm, A. and Vos, W. (2008). "New Technologies for Telematics and Machine Control." Proc. 1st Int. Conf. on Machine Control and Guidance, Zurich, Switzerland.

Tezel, A. and Aziz, Z. (2017). "Visual Management in Highways Construction and Maintenance in England." Engineering, Construction and Architectural Management, 24(3), 486-513.

Tezel, A., Koskela, L., and Aziz, Z. (2018). "Lean Thinking in the Highways Cconstruction Sector: Motivation, Implementation and Barriers." Production Planning \& Control, 29(3), 247-269.

Womack, J. P. and Jones, D. T. (1996). Lean Thinking: Banish Waste and Create Wealth in your Corporation. Touchstone books, London, UK. 